\title{
Detection of 6 TFEB-amplified renal cell carcinomas and 25 renal cell carcinomas with MITF translocations: systematic morphologic analysis of 85 cases evaluated by clinical TFE3 and TFEB FISH assays
}

Stephanie L Skala ${ }^{1}$, Hong Xiao ${ }^{1,2}$, Aaron M Udager ${ }^{1}$, Saravana M Dhanasekaran ${ }^{3}$, Sudhanshu Shukla ${ }^{3}$, Yang Zhang ${ }^{2}$, Carrie Landau ${ }^{2}$, Lina Shao ${ }^{1,2}$, Diane Roulston ${ }^{1,2}$, Lisha Wang ${ }^{3}$, Javed Siddiqui ${ }^{3}$, Xuhong $\mathrm{Cao}^{3}$, Cristina Magi-Galluzzi ${ }^{4}$, Miao Zhang ${ }^{5}$, Adeboye O Osunkoya ${ }^{6}$, Steven C Smith ${ }^{7}$, Jesse K McKenney ${ }^{4}$, Bryan L Betz ${ }^{1}$, Jeffrey L Myers ${ }^{1}$, Arul M Chinnaiyan ${ }^{1,3,8,9}$, Scott A Tomlins ${ }^{1,3,8}$ and Rohit Mehra ${ }^{1,3,8}$

${ }^{1}$ Department of Pathology, University of Michigan Health System, Ann Arbor, MI, USA; ${ }^{2}$ Clinical Cytogenetics Laboratory, University of Michigan Health System, Ann Arbor, MI, USA; ${ }^{3}$ Michigan Center for Translational Pathology, Ann Arbor, MI, USA; ${ }^{4}$ Pathology and Laboratory Medicine Institute, Cleveland Clinic, Cleveland, OH, USA; ${ }^{5}$ University of Texas—MD Anderson Cancer Center, Houston, TX, USA; ${ }^{6}$ Departments of Pathology and Urology, Emory University School of Medicine, Atlanta, GA, USA; ${ }^{7}$ Virginia Commonwealth University School of Medicine, Richmond, VA, USA; ${ }^{8}$ Comprehensive Cancer Center, University of Michigan Health System, Ann Arbor, MI, USA and ${ }^{9}$ Howard Hughes Medical Institute, Ann Arbor, MI, USA

Renal cell carcinomas with MITF aberrations demonstrate a wide morphologic spectrum, highlighting the need to consider these entities within the differential diagnosis of renal tumors encountered in clinical practice. Herein, we describe our experience with application of clinical fluorescence in situ hybridization (FISH) assays for detection of TFE3 and TFEB gene aberrations from 85 consecutive renal cell carcinoma cases submitted to our genitourinary FISH service. Results from 170 FISH assays performed on these tumors were correlated with available clinicopathologic findings. Ninety-eight percent of renal tumors submitted for FISH evaluation were from adult patients. Thirty-one (37\%) tumors were confirmed to demonstrate MITF aberrations (21 TFE3 translocation, 4 TFEB translocation, and 6 TFEB amplification cases). Overall, renal cell carcinomas with MITF aberrations demonstrated morphologic features overlapping with clear cell, papillary, or clear cell papillary renal cell carcinomas. Renal cell carcinomas with MITF aberrations were significantly more likely to demonstrate dual (eosinophilic and clear) cytoplasmic tones $(P=0.030)$, biphasic TFEB translocation renal cell carcinoma-like morphology $(P=0.002)$, psammomatous calcifications $(P=0.002)$, and nuclear pseudoinclusions $(P=0.001)$ than renal cell carcinomas without MITF aberrations. Notably, $7 / 9(78 \%)$ renal cell carcinomas exhibiting subnuclear clearing and linear nuclear array (6 of which showed high World Health Organization/International Society of Urological Pathology nucleolar grade) demonstrated TFE3 translocation, an association that was statistically significant when compared with renal cell carcinomas without MITF aberrations $(P=0.009)$. In this cohort comprising consecutive cases, TFEB-amplified renal cell carcinomas were more commonly identified than renal cell carcinomas with TFEB translocations, and four (67\%) of these previously unreported TFEB-amplified renal cell carcinomas demonstrated oncocytic and papillary features with a high World Health Organization/ International Society of Urological Pathology nucleolar grade. In summary, TFE3 and TFEB FISH evaluation aids in identification and accurate classification of renal cell carcinomas with MITF aberrations, including TFEB-amplified renal cell carcinoma, which may demonstrate aggressive behavior.

Modern Pathology (2018) 31, 179-197; doi:10.1038/modpathol.2017.99; published online 25 August 2017

Correspondence: Dr R Mehra, MD, Department of Pathology, University of Michigan Health System, Room 2G332 UH, 1500 E. Medical Center Drive, Ann Arbor, MI 48109, USA.

E-mail: mrohit@med.umich.edu

Received 1 May 2017; revised 16 June 2017; accepted 29 June 2017; published online 25 August 2017 
The field of kidney cancer diagnostic pathology has undergone significant transformation, with several studies revealing key genomic events underlying different subtypes of renal cell carcinoma. ${ }^{1-7}$ Indeed, what was initially considered to be a complete enumeration of tumors comprising only four diagnostic sub-entities has now evolved into a complex and clinically useful World Health Organization classification system of renal cell carcinoma, including several new and intriguing subtypes, such as MITF translocation renal cell carcinoma and tumors with recognized hereditary predispositions (eg, hereditary leiomyomatosis and renal cell carcinoma-associated renal cell carcinoma and succinate dehydrogenase-deficient renal cell carcinoma). ${ }^{1,8-10}$

TFE3 and TFEB are members of the melanogenesis-associated transcription factor (MITF) family of transcription factors. Gene fusions involving these transcription factors have been identified in renal cell carcinoma, with such tumors being currently classified as translocation renal cell carcinoma. ${ }^{1,7,11}$ TFE3 translocation renal cell carcinomas have been recognized by the World Health Organization since 2004, and TFEB translocation renal cell carcinomas have been recognized by the International Society of Urological Pathology since 2013. ${ }^{11}$ Although translocation renal cell carcinomas comprise approximately $40 \%$ of pediatric renal cell carcinomas, more cases of translocation renal cell carcinoma are seen in adults due to the higher overall incidence of renal cell carcinoma in this population. ${ }^{7}$ The exact incidence of TFE3 translocation renal cell carcinoma among adults remains debatable but estimates range from 1 to $4 \%$ of all renal cell carcinoma, with approximately 2500 new cases diagnosed every year. ${ }^{7,12,13}$ A subset of patients might also develop translocation renal cell carcinoma after chemotherapy and/or treatment for neuroblastoma. ${ }^{14}$ In adults, TFE3 translocation renal cell carcinoma is an aggressive tumor with overall survival similar to that of clear cell renal cell carcinoma. ${ }^{11,12,15}$ TFEB translocation renal cell carcinomas typically occur at a relatively young age $(\text { median }=31 \text { years })^{7,15}$ and, based on the cases reported in the literature, may have a better overall prognosis than TFE3 translocation renal cell carcinoma. More recently, renal cell carcinomas with TFEB amplification have been identified and appear to be associated with a more aggressive clinical course than TFEB translocation renal cell carcinoma. ${ }^{16-18}$ Because of their relatively recent identification, such renal cell carcinomas with TFEB amplification have not been given a formal name or included in the World Health Organization classification of renal cell carcinoma; ${ }^{1,16,17}$ however, their reported association with poor outcome suggests a clinical need for identifying these cases prospectively, with confirmation of TFEB amplification using FISH or next-generation sequencing assays. Indeed, description of associated clinicopathologic features of such TFEB-amplified renal cell carcinoma cases confirmed at the genotypic level will allow better recognition of such tumors in daily clinical practice.

Immunohistochemical evaluation for TFE3 and TFEB proteins, although relatively sensitive and specific, is currently considered less reliable than FISH for detection of MITF aberrations, predominantly because immunohistochemical results are vulnerable to fixation effects. ${ }^{19-22}$ Dual-color breakapart FISH has been effectively used to facilitate an accurate diagnosis of translocation renal cell carcinoma and demonstrates a high degree of specificity and sensitivity (except in cases with subtle intrachromosomal translocations, as may be seen with TFE3 fusion partners such as NONO and RBM10). ${ }^{23,24}$ Importantly, TFEB amplification events can be detected by FISH but likely cannot be differentiated from TFEB translocation renal cell carcinoma based on IHC, as TFEB overexpression by IHC has been demonstrated in a large subset of reported cases. ${ }^{16,17}$ Herein, we share our experience with application of clinical FISH assays for detection of TFE3 and TFEB aberrations in a large consecutive cohort of cases clinically, morphologically, and/or immunophenotypically suspicious for translocation renal cell carcinoma. We describe six new genotypically proven $T F E B$-amplified renal cell carcinoma cases and report morphologic features that may aid in the identification of renal cell carcinomas with MITF aberrations, including the presence of nuclear pseudoinclusions.

\section{Materials and methods}

\section{Case Selection}

The genitourinary service line laboratory currently in operation at Michigan Medicine was developed in order to provide definitive diagnostic services for inhouse and consultation cases, as well as outside cases requiring only molecular analysis. ${ }^{19}$ After approval from the Institutional Review Board, 85 consecutive, unselected consultation and in-house renal tumors suspicious for translocation renal cell carcinoma (on clinical and/or morphologic and immunophenotypic grounds) and submitted for TFE3 and TFEB FISH service for investigation of MITF gene aberrations were collected. For each tumor, numerous morphologic features were assessed, including predominant architectural pattern, entrapped benign renal tubules, dual (eosinophilic and clear) cytoplasmic tones, biphasic morphology with smaller cells surrounding basement membrane material (TFEB translocation renal cell carcinoma-like), presence of subnuclear clearing and linear nuclear array, oncocytic features, voluminous clear and/or eosinophilic cytoplasm, psammomatous calcifications, foamy histiocytes, necrosis, sarcomatoid differentiation, nuclear pseudoinclusions, 
and cytoplasmic vacuolization. The diagnosis felt to be most representative of the morphology of each tumor was recorded as the top differential diagnosis. Multiple slides of tumor were evaluated for in-house cases and cases sent for morphologic consultation; however, only one H\&E slide was typically available for review from those cases that were sent from referring institutions for FISH analysis only. Similarly, while the entire case was available for review for in-house cases, limited immunohistochemical stains and clinical information were available for some of the outside cases. Regardless, immunophenotypic details related to carbonic anhydrase IX, Melan-A, HMB-45, and pancytokeratin were available for the majority of patients. All available immunohistochemical and clinical information was recorded and correlated with TFE3 and TFEB status as determined by FISH analysis.

\section{FISH Probe Design and Development}

Interphase FISH was performed using commercial dual-color break-apart probes from Empire Genomics (Buffalo, NY, USA) specific to the TFE3 gene locus at Xp11.2 (TFE3 assay) and to the TFEB locus at 6p21 (TFEB assay) employing previously established methodologies. ${ }^{19,25-28}$ The probe mixture in each assay includes one probe located centromeric (5 prime) and one probe located telomeric ( 3 prime) to the breakpoint region of interest. Splitting of the probes is observed when a translocation/rearrangement is present.

\section{FISH Hybridization and Detection}

Four-micron-thick formalin-fixed, paraffinembedded sections were processed for these assays. The slides were baked overnight at $56-60{ }^{\circ} \mathrm{C}$. On day 2, $10 \mathrm{mM}$ sodium citrate/2 mM EDTA was heated to $80{ }^{\circ} \mathrm{C}$ with a water bath and $0.01 \mathrm{~N} \mathrm{HCl}$ was heated to $37^{\circ} \mathrm{C}$. Slides were immersed in fresh xylene for $10 \mathrm{~min}$, three times. The slides were then air dried for 2-5 min before being dehydrated in $100 \% \mathrm{EtOH}$ for $5 \mathrm{~min}$, twice, and air dried again. The slides were then incubated in $0.2 \mathrm{~N} \mathrm{HCl}$ at room temperature for $30 \mathrm{~min}$, then $10 \mathrm{mM}$ sodium citrate $(\mathrm{pH} 6.4) / 2 \mathrm{mM}$ EDTA (pH 8.0) at $80^{\circ} \mathrm{C}$ for $45 \mathrm{~min}$. After this, slides were immersed in $2 \times$ SSC at room temperature for $2 \mathrm{~min}$, and then rinsed in distilled $\mathrm{H} 2 \mathrm{O}$ for $10 \mathrm{~min}$. The slides were then incubated in $0.2 \mathrm{~N} \mathrm{HCl}$ at room temperature for $2 \mathrm{~min}$ followed by protease pretreatment. About $0.5 \mathrm{ml} 75000 \mathrm{U} / \mathrm{ml}$ pepsin solution was added to $49.5 \mathrm{ml} 0.01 \mathrm{~N} \mathrm{HCl}$ solution, and slides were incubated at $37^{\circ} \mathrm{C}$ for $15-20 \mathrm{~min}$. After this step, the slides were immediately immersed in distilled $\mathrm{H}_{2} \mathrm{O}$ at room temperature for $10 \mathrm{~min}$. Next, the slides were dehydrated in ascending EtOH solution $(70,85$, and $100 \%$ EtOH solutions for $2 \mathrm{~min}$ each at room temperature). The slides were then air dried, and tissue morphology was assessed.
The probe mixes were prepared as instructed, and 10-15 $\mu \mathrm{l}$ of probe mix were applied to slides. The slides were coverslipped and sealed with rubber cement. The slides and probes were then codenatured for $10 \mathrm{~min}$ at $75^{\circ} \mathrm{C}$ and hybridized for $16 \mathrm{~h}$ at $37^{\circ} \mathrm{C}$. The next day, the rubber cement was removed and slides were rinsed in $0.4 \times \mathrm{SSC}$ at $73{ }^{\circ} \mathrm{C}$ for $2 \mathrm{~min}$, followed by $2 \times \mathrm{SSC} / 0.1 \% \mathrm{NP} 40$ at room temperature for $2 \mathrm{~min}$. The slides were then air dried in the dark, and $25 \mu \mathrm{l}$ of DAPI counterstain was added to the target area before a coverslip was applied.

\section{FISH Evaluation}

In our clinical practice, two known negative controls, two known positive controls, and two samples (in duplicate) from the tumor under investigation are hybridized for TFE3 and/or TFEB FISH and analyzed at the same time. Two technologists score probe signals in 200 total interphase nuclei and the number of target and control signals as well as their localization in each cell is recorded on the FISH analysis sheet. Cases are interpreted according to normal cutoff values determined by the laboratory using the beta inverse function calculation based on the normal control case with the highest number of observed abnormal cells. All cases are provided a final interpretation, confirmation and sign-out by genitourinary pathologists with extensive experience with FISH methodology and analysis (SAT and RM). The expected positive signal pattern for the TFE3 assay differs between male and female patients due to involvement of the X chromosome; females with a TFE3 translocation should show one red, one green, and one fusion (yellow) signal, whereas males show one red and one green signal. The expected negative signal pattern is two fusion (yellow) signals for a female or one fusion (yellow) signal for a male. The expected positive signal pattern for the TFEB assay is one red, one green, and one fusion (yellow) signal, whereas the expected negative signal is two fusion (yellow) signals. An amplified TFEB signal was defined as $>10$ TFEB signals, as previously described by Argani et al. ${ }^{16}$

\section{Statistics}

Associations between TFE3 and TFEB FISH data and specific morphologic features were examined using the $\chi^{2}$ test or Fisher's exact test, as indicated; a $P$-value $<0.05$ was considered statistically significant.

\section{Results}

For the overall cohort, the mean age at renal cell carcinoma diagnosis was 52 years (range 12-85 years), with only two patients less than 18-yearsold. Thirty-one of 85 (37\%) tumors showed MITF 
Table 1 Detailed morphology of renal cell carcinoma cases submitted for TFE3 and/or TFEB FISH

\begin{tabular}{|c|c|c|c|c|}
\hline & $\begin{array}{l}\text { TFE3 translocation } \\
\qquad(\mathrm{n}=21)\end{array}$ & $\begin{array}{c}\text { TFEB translocation } \\
(\mathrm{n}=4)\end{array}$ & $\begin{array}{c}\text { TFEB amplification } \\
(\mathrm{n}=6)\end{array}$ & $\begin{array}{l}\text { No detected MITF } \\
\text { aberration }(\mathrm{n}=54)\end{array}$ \\
\hline Predominant nested architecture & $7 / 21(33 \%)$ & $2 / 4(50 \%)$ & $2 / 6(33 \%)$ & $13 / 54(24 \%)$ \\
\hline Predominant papillary architecture & $8 / 21(38 \%)$ & $2 / 4(50 \%)$ & $4 / 6(67 \%)$ & $21 / 54(39 \%)$ \\
\hline Predominant pseudopapillary architecture & $4 / 21(19 \%)$ & $0 / 4(0 \%)$ & $0 / 6(0 \%)$ & $17 / 54(32 \%)$ \\
\hline Predominant solid architecture & $0 / 20(0 \%)$ & $0 / 4(0 \%)$ & $0 / 6(0 \%)$ & $2 / 54(4 \%)$ \\
\hline Predominant cystic architecture & $1 / 21(5 \%)$ & $0 / 4(0 \%)$ & $0 / 6(0 \%)$ & $0 / 54(0 \%)$ \\
\hline Predominant trabecular architecture & $0 / 20(0 \%)$ & $0 / 4(0 \%)$ & $0 / 6(0 \%)$ & $1 / 54(2 \%)$ \\
\hline Predominant tubular architecture & $1 / 21(5 \%)$ & $0 / 4(0 \%)$ & $0 / 6(0 \%)$ & $0 / 54(0 \%)$ \\
\hline Entrapped benign renal tubules & $4 / 20(20 \%)$ & $4 / 4(100 \%)$ & $3 / 6(50 \%)$ & $16 / 52(31 \%)$ \\
\hline Dual (eosinophilic and clear) cytoplasmic tones & $16 / 21(76 \%)$ & $4 / 4(100 \%)$ & $5 / 6(83 \%)$ & $31 / 54(57 \%)$ \\
\hline Biphasic TFEB t-RCC-like & $4 / 21(19 \%)$ & $2 / 4(50 \%)$ & $0 / 6(0 \%)^{a}$ & $0 / 54(0 \%)$ \\
\hline Subnuclear clearing and linear nuclear array & $7 / 21(33 \%)$ & $0 / 4(0 \%)$ & $0 / 6(0 \%)^{b}$ & $4 / 54(7 \%)$ \\
\hline Oncocytic features & $5 / 21(24 \%)$ & $0 / 4(0 \%)$ & $4 / 6(67 \%)$ & $22 / 54(41 \%)$ \\
\hline Voluminous clear and/or eosinophilic cytoplasm & $19 / 21(91 \%)$ & $3 / 4(75 \%)$ & $4 / 6(67 \%)$ & $37 / 54(69 \%)$ \\
\hline Psammomatous calcifications & $14 / 21(67 \%)$ & $4 / 4(100 \%)$ & $1 / 6(17 \%)$ & $14 / 54(26 \%)$ \\
\hline Foamy histiocytes & $4 / 21(19 \%)$ & $0 / 4(0 \%)$ & $3 / 6(50 \%)$ & $22 / 54(41 \%)$ \\
\hline Necrosis & $9 / 21(43 \%)$ & $1 / 4(25 \%)$ & $4 / 6(67 \%)$ & $26 / 54(48 \%)$ \\
\hline Sarcomatoid differentiation & $2 / 21(10 \%)$ & $0 / 4(0 \%)$ & $1 / 6(17 \%)$ & $5 / 54(9 \%)$ \\
\hline Nuclear pseudoinclusions & $12 / 21(57 \%)^{\mathrm{C}}$ & $1 / 4(25 \%)$ & $3 / 6(50 \%)^{\mathrm{C}}$ & $9 / 54(17 \%)^{\mathrm{C}}$ \\
\hline Cytoplasmic vacuolization & $19 / 21(91 \%)$ & $4 / 4(100 \%)$ & $6 / 6(100 \%)$ & $47 / 54(87 \%)$ \\
\hline
\end{tabular}

${ }^{\mathrm{a} O n e}$ case had foci with smaller cells forming acinar structures, but no basement membrane material.

${ }^{b}$ Four additional cases had foci with orderly polarization of nuclei in the mid to apical aspects of oncocytic cells.

${ }^{\mathrm{C}}$ Nuclear pseudoinclusions were extensive in focal nodules in 1 of 12 TFE3 translocation RCCs with this feature. Of the remaining cases with nuclear pseudoinclusions, this feature was extensive in one of three TFEB-amplified RCCs and one of nine RCCs without a detected MITF aberration.

aberrations, including TFE3 translocation $(n=21)$, TFEB translocation $(n=4)$, and TFEB amplification $(n=6)$. Renal cell carcinomas with MITF aberrations demonstrated a spectrum of morphologic features overlapping with clear cell, papillary, and clear cell papillary renal cell carcinomas (Table 1).

\section{TFEB-Amplified Renal Cell Carcinoma}

FISH analyses demonstrated TFEB amplification in tumors from six patients (7\%) in this cohort; a majority of the tumor cells (more than 50\%) showed TFEB amplification, and there was no evidence of TFEB translocation in these cases. The mean age at diagnosis for these six patients was 65 years (range 48-72 years), with a 2:1 male-to-female ratio. The mean tumor size was $7.9 \mathrm{~cm}$ (range $=5.5-12.2 \mathrm{~cm}$ ). One tumor was stage pT2b, four tumors were stage pT3a, and one tumor was clinical stage T4 with radiographic evidence of regional nodal and distant visceral metastases. TFEB-amplified renal cell carcinoma showed variable morphology with high World Health Organization/International Society of Urological Pathology nucleolar grade (four grade 3 and two grade 4). The predominant tumor architecture was papillary in four cases and nested in two cases. The top differential diagnosis based upon morphologic evaluation was papillary renal cell carcinoma in four cases and clear cell renal cell carcinoma in two cases. Detailed clinical information, morphologic features, and immunohistochemical results of these six newly reported TFEB-amplified renal cell carcinoma cases are described below and presented in Supplementary Table S1; morphologic features are summarized in Table 1. Representative photomicrographs are presented in Figures 1 and 2.

Case 1. A 68-year-old woman had a radical nephrectomy to remove a $6.5 \mathrm{~cm}$, pT3aNX, World Health Organization/International Society of Urological Pathology nucleolar grade 3 tumor with papillary architecture, entrapped benign renal tubules, predominantly oncocytic features but with focal dual (eosinophilic and clear) cytoplasmic tones, foci with smaller cells forming acinar structures (without basement membrane material), voluminous cytoplasm, vacuolated cytoplasm, focal microscopic necrosis, and focal nuclear pseudoinclusions. The top morphologic differential diagnosis considered was papillary renal cell carcinoma. Photomicrographs are presented in Figure 2d-f. Immunohistochemical work-up demonstrated positive cathepsin $\mathrm{K}$, patchy cytokeratin and Melan-A, and negative carbonic anhydrase IX, CD117 and CK7 expression.

Case 2. A 65-year-old man had a partial nephrectomy to remove a $5.5 \mathrm{~cm}$, pT3aNX, World Health Organization/International Society of Urological Pathology nucleolar grade 3 tumor with nested architecture, dual (eosinophilic and clear) cytoplasmic tones, voluminous cytoplasm, cytoplasmic vacuolation, and focal psammomatous calcification, foamy histiocytes, and nuclear pseudoinclusions. The top morphologic differential diagnosis considered was clear cell renal cell carcinoma. A photomicrograph is presented in Figure 1e. Immunohistochemical staining for cathepsin $\mathrm{K}$ was positive, with negative carbonic anhydrase IX and CK7 expression. 

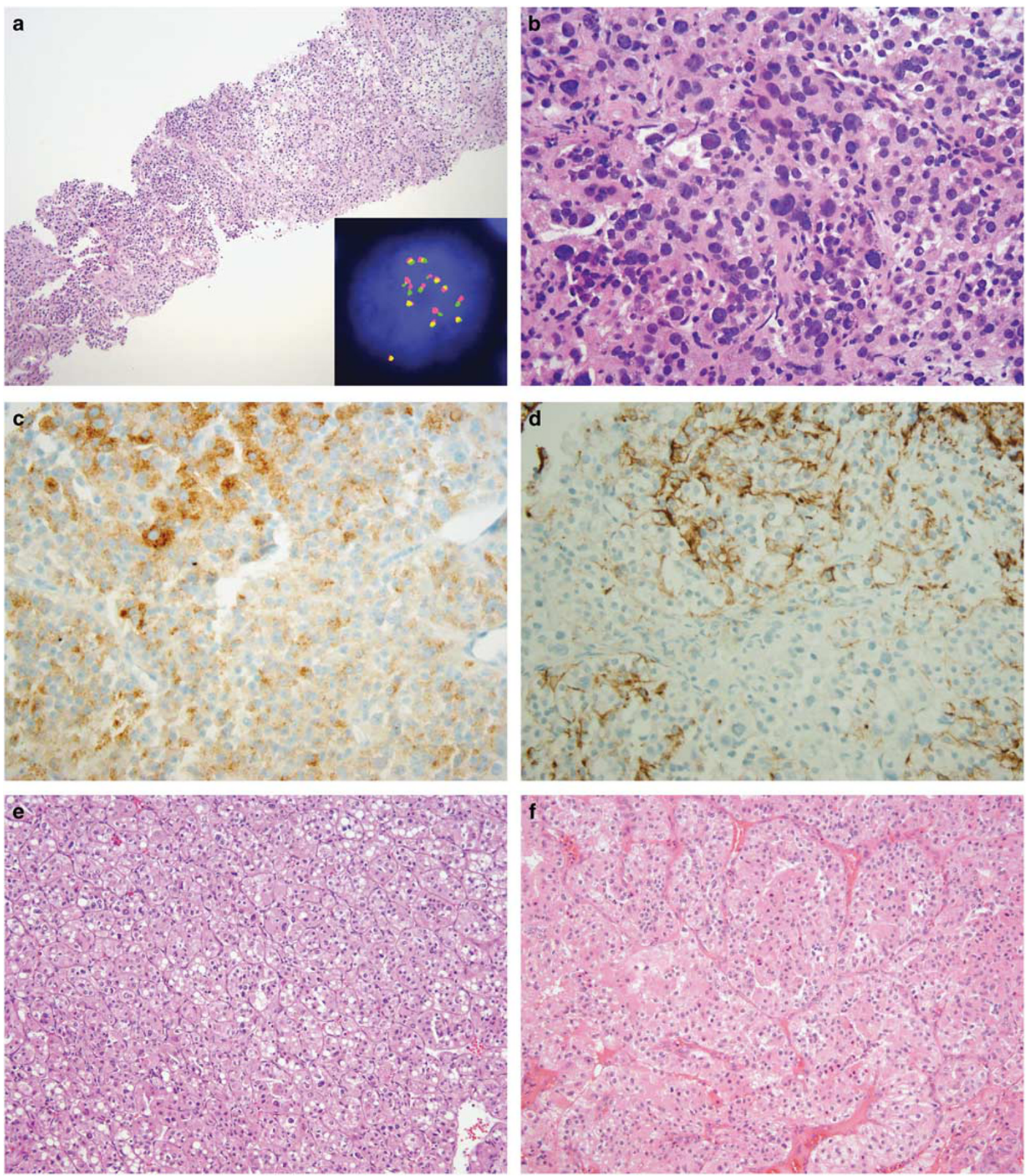

Figure 1 TFEB-amplified renal cell carcinomas with representative immunohistochemical stains. (a) In-house TFEB-amplified renal cell carcinoma with features of poorly differentiated carcinoma (Case 4), H\&E, $\times 100$ (inset: TFEB FISH demonstrating amplification); (b) H\&E, $\times$ 400. Immunohistochemical work-up demonstrated (c) patchy Melan-A expression, $\times 400$, and (d) patchy pancytokeratin expression, $\times$ 400. Similarly, Case 2 also demonstrated predominantly nested architecture and resembled high-grade clear cell renal cell carcinoma (e) $\mathrm{H} \& \mathrm{E}, \times 200$. Case 3 showed oncocytic and papillary morphology (f) H\&E, $\times 200$.

Case 3. A 48-year-old woman had a radical nephrectomy to remove a $10.1 \mathrm{~cm}$, pT2bNX, World Health Organization/International Society of Urological Pathology nucleolar grade 4 tumor with predominantly papillary (and focally tubular) architecture, oncocytic features, cytoplasmic vacuolation, and foci of foamy histiocytes, microscopic necrosis, voluminous cytoplasm, and dual (eosinophilic and 

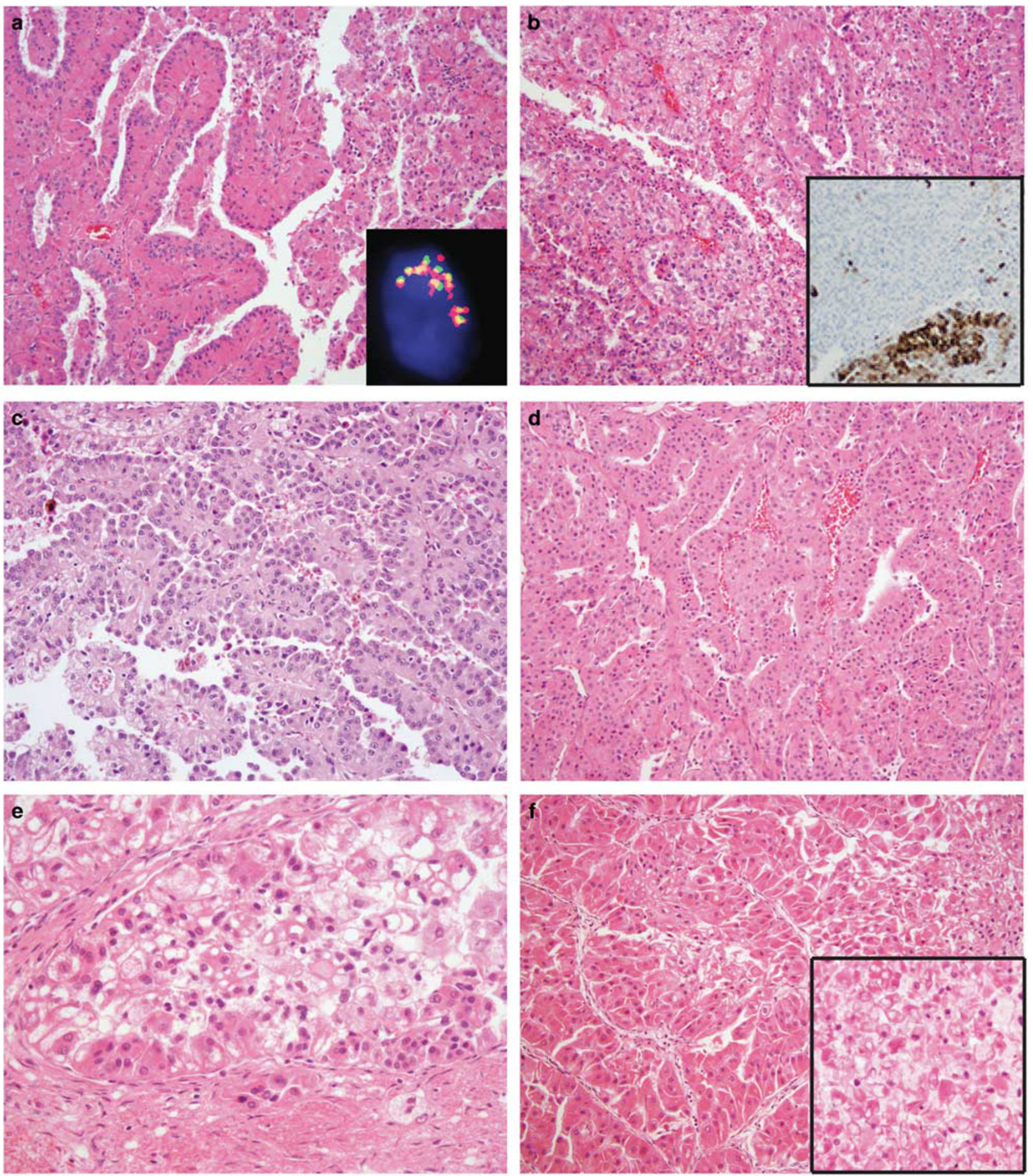

Figure 2 Morphologic spectrum of TFEB-amplified renal cell carcinoma, including (a, b) high-grade oncocytic and papillary morphology with foci of orderly polarization of nuclei in the mid to apical aspect of oncocytic cells (Case 6), H\&E, $\times 200$ (inset of a: TFEB FISH demonstrating amplification). Immunohistochemical work-up demonstrated patchy Melan-A expression (inset of b, $\times 100$ ). Two other high-grade tumors with papillary and oncocytic features including orderly polarization of nuclei in the mid to apical aspect of oncocytic cells are depicted in (c) H\&E from Case 5, × 200, and (d) H\&E from Case 1, × 200. Case 1 also demonstrated areas of dyscohesion and cells with cytoplasmic vacuoles $(\mathbf{e}, \mathrm{H} \& \mathrm{E}, \times 200$; inset: H\&E, $\times 200)$, as well as focal areas of smaller cells forming acinar structures $(\mathbf{f}, \mathrm{H} \& \mathrm{E}, \times 400)$.

clear) cytoplasmic tones. Within the oncocytic and papillary areas, there were foci with orderly polarization of nuclei in the mid to apical aspect of cells. The top morphologic differential diagnosis considered was papillary renal cell carcinoma. Photomicrographs are presented in Figure 1f. Immunohistochemical work-up demonstrated patchy expression of pancytokeratin, Melan-A, and carbonic anhydrase IX. 
Case 4. A 68-year-old man had a needle biopsy of a $12.2 \mathrm{~cm}$ renal mass, performed at our institution. At presentation, he had clinical T4N1M1 disease. Morphologically, the tumor was nested and poorly differentiated with World Health Organization/International Society of Urological Pathology nucleolar grade 4. Prominent features included dual (eosinophilic and clear) cytoplasmic tones, cytoplasmic vacuolation, extensive nuclear pseudoinclusions, and focal sarcomatoid differentiation. The top morphologic differential diagnosis considered was high-grade clear cell renal cell carcinoma, although metastatic melanoma from an unknown primary was also considered. Photomicrographs are presented in Figure 1a-d. Immunohistochemical work-up demonstrated positive expression of pancytokeratin, PAX8, Melan-A, and CD117 but no reactivity for carbonic anhydrase IX or HMB-45.

Case 5. A 72-year-old man had a radical nephrectomy to remove a $7.0 \mathrm{~cm}$, pT3aNX, World Health Organization/International Society of Urological Pathology nucleolar grade 3 tumor with papillary architecture, oncocytic features, and cytoplasmic vacuolation, as well as foci of foamy histiocytes and microscopic necrosis. There were foci with somewhat orderly polarization of nuclei in the mid to apical aspect of oncocytic cells. The top morphologic differential diagnosis considered was papillary renal cell carcinoma. A photomicrograph is presented in Figure 2c. Immunohistochemical work-up demonstrated positive PAX8, patchy Melan-A, and absent carbonic anhydrase IX, epithelial membrane antigen, CD117, and CK7 expression.

Case 6. A 69 year-old man had a radical nephrectomy to remove a $5.9 \mathrm{~cm}$, pT3aN1, World Health Organization/International Society of Urological Pathology nucleolar grade 3 tumor with papillary architecture, oncocytic features, dual cytoplasmic tones, entrapped benign renal tubules, voluminous cytoplasm, necrosis, and focal cytoplasmic vacuolation. There were focal areas in which oncocytic cells with voluminous cytoplasm showed orderly polarization of nuclei in the mid to apical aspect of cells. The top morphologic differential diagnosis considered was papillary renal cell carcinoma. Representative photomicrographs are presented in Figure 2a and b. Immunohistochemical work-up demonstrated patchy Melan-A, patchy pancytokeratin, and absent carbonic anhydrase IX expression.

\section{TFEB Translocation Renal Cell Carcinoma}

FISH analyses demonstrated TFEB translocation in tumors from four patients $(5 \%)$ in this cohort; the mean percentage of tumor cells showing TFEB translocation was $80 \%$ (range $=59-92 \%$ ), and no TFEB amplifications were identified in these cases. The mean age at diagnosis for these four patients was
41 years (range 34-51 years), with a 1:1 male-tofemale ratio. All FISH diagnoses were rendered on resections (1 partial nephrectomy and 3 radical nephrectomies). The mean tumor size was $4.5 \mathrm{~cm}$ (range $=1.2-8.5 \mathrm{~cm}$ ). One tumor was locally advanced (pT3a), whereas the other three were confined to the kidney (pT2 or below). All four tumors were World Health Organization/International Society of Urological Pathology nucleolar grade 3. Detailed clinical information is presented in Supplementary Table S1; morphologic features are summarized in Table 1.

Morphologically, the predominant architecture was papillary in two cases and nested in two cases. The top morphologic differential diagnoses were: TFEB translocation renal cell carcinoma (3) and papillary renal cell carcinoma (1). All cases showed entrapped benign renal tubules, dual (eosinophilic and clear) cytoplasmic tones, psammomatous calcifications, and cytoplasmic vacuolization. Three cases showed voluminous cytoplasm. Two cases showed the biphasic TFEB translocation renal cell carcinoma-like morphology with smaller cells surrounding basement membrane material. One case showed microscopic necrosis. One case showed focal nuclear pseudoinclusions. No cases showed subnuclear clearing and linear nuclear array, oncocytic features, collections of foamy histiocytes, or sarcomatoid differentiation. Representative photomicrographs are presented in Figure 3.

Ancillary immunohistochemical work-up demonstrated pancytokeratin expression in two of the three evaluated cases; the fourth case was negative for epithelial membrane antigen expression. Melan-A was positive in three of the four cases that were stained, and one of those three cases was also positive for HMB-45. Carbonic anhydrase IX expression was negative in all four cases.

\section{TFE3 Translocation Renal Cell Carcinoma}

FISH analyses demonstrated TFE3 translocation in tumors from 21 patients $(26 \%)$ in this cohort; the mean percentage of tumor cells showing TFE3 translocation was $82 \%$ (range $=40-97 \%$ ), and no TFE3 amplifications were identified. The mean age at diagnosis for these 21 patients was 49 years (range 17-70 years), with a 1:2 male-to-female ratio. FISH diagnoses were rendered on variable specimen types, including three needle biopsies (two from the primary renal mass and one from a liver metastasis); the remainder of specimens were resections (partial or radical nephrectomies) of the primary tumor. The mean tumor size was $5.8 \mathrm{~cm}$ (range $=1.7-16.8 \mathrm{~cm}$ ). The majority of tumors were of high World Health Organization/International Society of Urological Pathology nucleolar grade (2 grade 2, 16 grade 3, and 3 grade 4). Nine patients had locally advanced primary tumors (pT3 or above, $n=7$ ) and/or evidence of metastatic disease $(n=4)$, whereas 11 patients had 

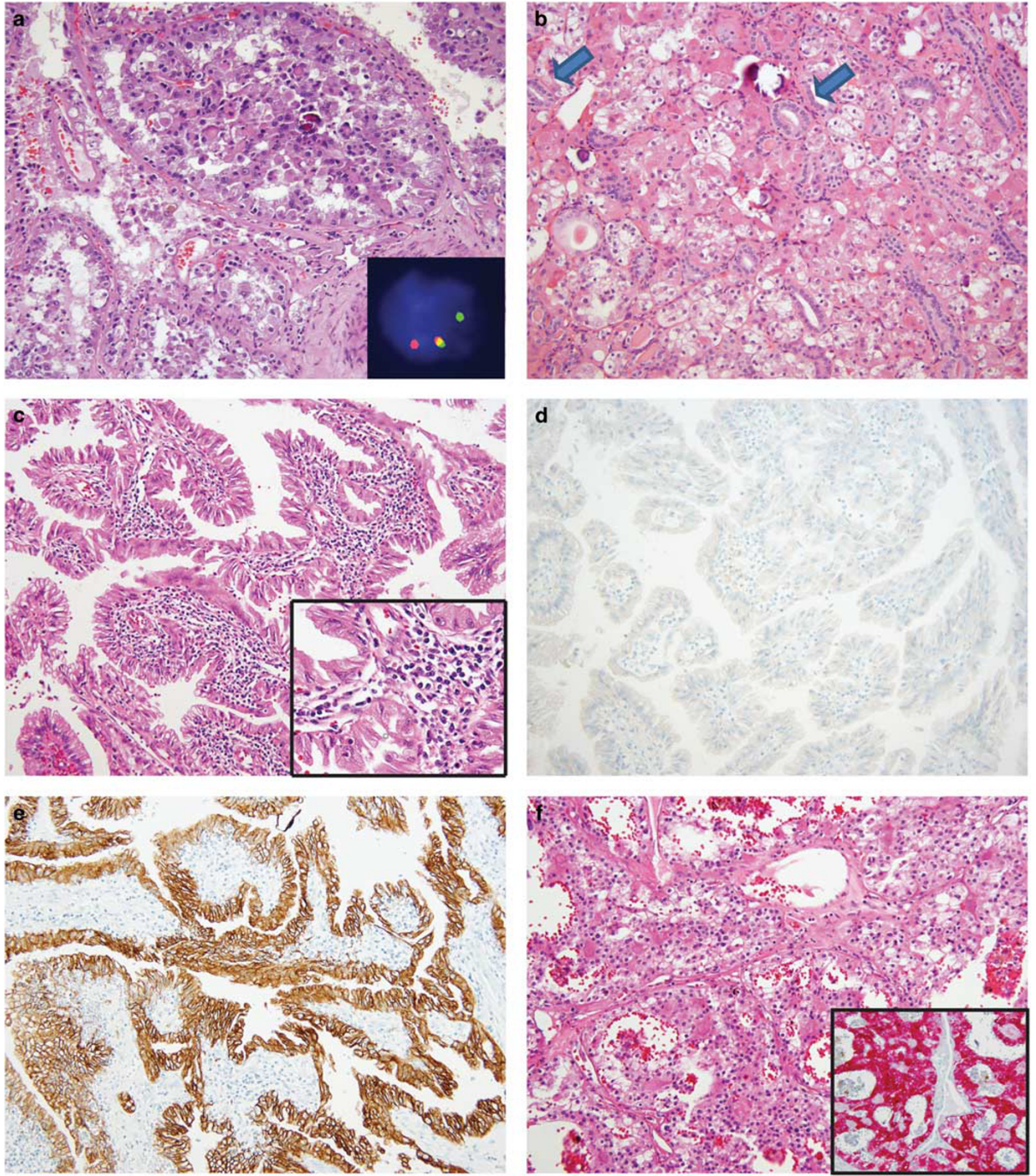

Figure 3 TFEB translocation renal cell carcinomas. Two tumors (a, b) show nested architecture and entrapped benign renal tubules, one (a) with the classic biphasic morphology including smaller cells surrounding basement membrane material. H\&E, $\times 200$. Inset of (a) shows TFEB FISH with split red and green signals indicating translocation. Two tumors (c, f), show papillary architecture. One (c) shows serrated eosinophilic epithelium and prominent lymphocytic infiltrate without significant collections of histiocytes within papillary cores, H\&E, $\times 200$, inset: H\&E, $\times 400$. Immunohistochemical stains demonstrate case (c) to be (d) negative for Melan-A, $\times 200$ and (e) diffusely positive for pancytokeratin, $\times 200$. Case (f) is positive for Melan-A (inset of $\mathbf{f}$ ).

tumors that were confined to the kidney (pT2 or below) without evidence of metastasis. Of the seven cases with available clinical follow-up, only one patient (Case 9: 20-year-old female with pT3aNXM1 TFE3 translocation renal cell carcinoma at presentation) died of disease. Detailed clinical information is 
presented in Supplementary Table S1; morphologic features are summarized in Table 1.

Morphologically, the predominant architecture was papillary in eight cases, nested in seven cases, pseudopapillary in four cases, cystic in one case, and tubular in one case. The top morphologic differential diagnoses considered were TFE3 translocation renal cell carcinoma (6), clear cell renal cell carcinoma (5), clear cell papillary renal cell carcinoma (2), papillary renal cell carcinoma (2), unclassified renal cell carcinoma (3), oncocytic renal cell carcinoma (1), and TFEB translocation renal cell carcinoma (2). Seven cases showed subnuclear clearing and linear nuclear array at least focally (including two with diffuse features; Figure 4), and all but one of these cases demonstrated high World Health Organization/ International Society of Urological Pathology nucleolar grade. Indeed, TFE3 translocation renal cell carcinomas account for $78 \%$ (7/9) of renal cell carcinomas with at least focal subnuclear clearing and linear nuclear array in our overall cohort. Four cases had at least focal areas with TFEB translocation renal cell carcinoma-like morphology (biphasic appearance with smaller cells surrounding basement membrane material; Figure 5). Entrapped benign renal tubules were present in four cases. One TFE3 translocation renal cell carcinoma with unique morphology was seen in a patient with a horseshoe kidney (Figure 6); this tumor was nested and solid with clear cells, large vacuoles, eccentric nuclei, and eosinophilic to clear cytoplasm, and there were focal pockets of cells with a high nucleus-to-cytoplasm ratio and eosinophilic cytoplasm. Another tumor demonstrated large nests with an unusual biphasic appearance including central streaming spindled cells on biopsy of a liver metastasis (Figure 4). Voluminous cytoplasm was common (diffuse in 16 cases and focal in 2 cases). Sixteen cases showed at least focal dual (eosinophilic and clear) cytoplasmic tones, and five cases had oncocytic features. Twelve cases demonstrated nuclear pseudoinclusions (focal in 11 and extensive in 1). Nineteen cases showed cytoplasmic vacuolization. Psammomatous calcifications were present in 14 cases. Four cases showed focal collections of foamy histiocytes, and microscopic necrosis was present in nine cases. Two cases showed focal sarcomatoid differentiation. Representative photomicrographs are presented in Figures 4-6.

Ancillary immunohistochemical work-up demonstrated that many cases in our cohort lack pancytokeratin expression; however, $44 \%$ show some degree of pancytokeratin expression ( 2 diffuse and 5 patchy; $n=16$ ). Melan-A was focally positive in 2 of the 17 evaluated cases, and similarly, HMB-45 was focally positive in 3 of the 13 evaluated cases. Carbonic anhydrase IX was not diffusely positive in any of the 12 tumors that were interrogated, but patchy/focal expression was present in 3 tumors, where it was localized to areas of microscopic necrosis.

\section{Renal Cell Carcinomas without MITF Aberrations}

FISH analyses did not detect a TFE3 or TFEB aberration in 54 patients (64\%) in this cohort. The mean age at diagnosis for these 54 patients was 52 years (range 12-85 years), with a 1.7:1 male-to-female ratio. FISH diagnoses were rendered on variable specimen types including one liver metastasis biopsy and one left supraclavicular lymph node metastasis excision; the remainder of specimens were resections (partial or radical nephrectomies) of the primary tumor. The mean tumor size was $6.4 \mathrm{~cm}$ (range $=1.4-30 \mathrm{~cm} ; n=48$ ). The vast majority of tumors were high World Health Organization/International Society of Urological Pathology nucleolar grade (3 grade 2, 41 grade 3, 10 grade 4 , and 1 for which grade was not applicable). Twenty tumors were locally advanced (pT3a or above), 30 were confined to the kidney (pT2 or below), and 4 lacked information about stage. Detailed clinical information is presented in Supplementary Table S1; morphologic features are summarized in Table 1.

Microscopically, the predominant architecture was papillary $(n=21)$, pseudopapillary $(n=17)$, nested $(n=13)$, solid $(n=2)$, or trabecular $(n=1)$. The top morphologic differential diagnoses considered were: papillary renal cell carcinoma (17, including 3 with oncocytic features), clear cell renal cell carcinoma (12), oncocytic renal cell carcinoma (12), unclassified renal cell carcinoma (6), TFE3 translocation renal cell carcinoma (3), clear cell papillary renal cell carcinoma (1), chromophobe renal cell carcinoma (1), hereditary leiomyomatosis and renal cell carcinoma-associated renal cell carcinoma (1), and eosinophilic, solid, and cystic renal cell carcinoma (1). Sixteen of 52 kidney resections showed entrapped benign renal tubules. Thirty-one cases showed dual (eosinophilic and clear) cytoplasmic tones. Four cases had subnuclear clearing and linear nuclear array (diffuse in 1 case and focal in 3 cases). Twenty-two cases had oncocytic features. Thirty-seven cases had at least focally voluminous cytoplasm. Fourteen cases had psammomatous calcifications. Twenty-two cases had collections of foamy histiocytes. Twenty-six cases had microscopic necrosis. Five cases showed focal sarcomatoid differentiation. Nine cases showed nuclear pseudoinclusions (8 focal, 1 extensive). Forty-seven cases showed cytoplasmic vacuolization. No cases showed the biphasic TFEB translocation renal cell carcinoma-like morphology. Representative photomicrographs are presented in Figure 7.

Ancillary immunohistochemical work-up demonstrated lack of pancytokeratin expression in 5 of the 30 evaluated cases. Six of 36 stained cases showed focal Melan-A expression, and HMB-45 was positive in 2 of 27 cases. 

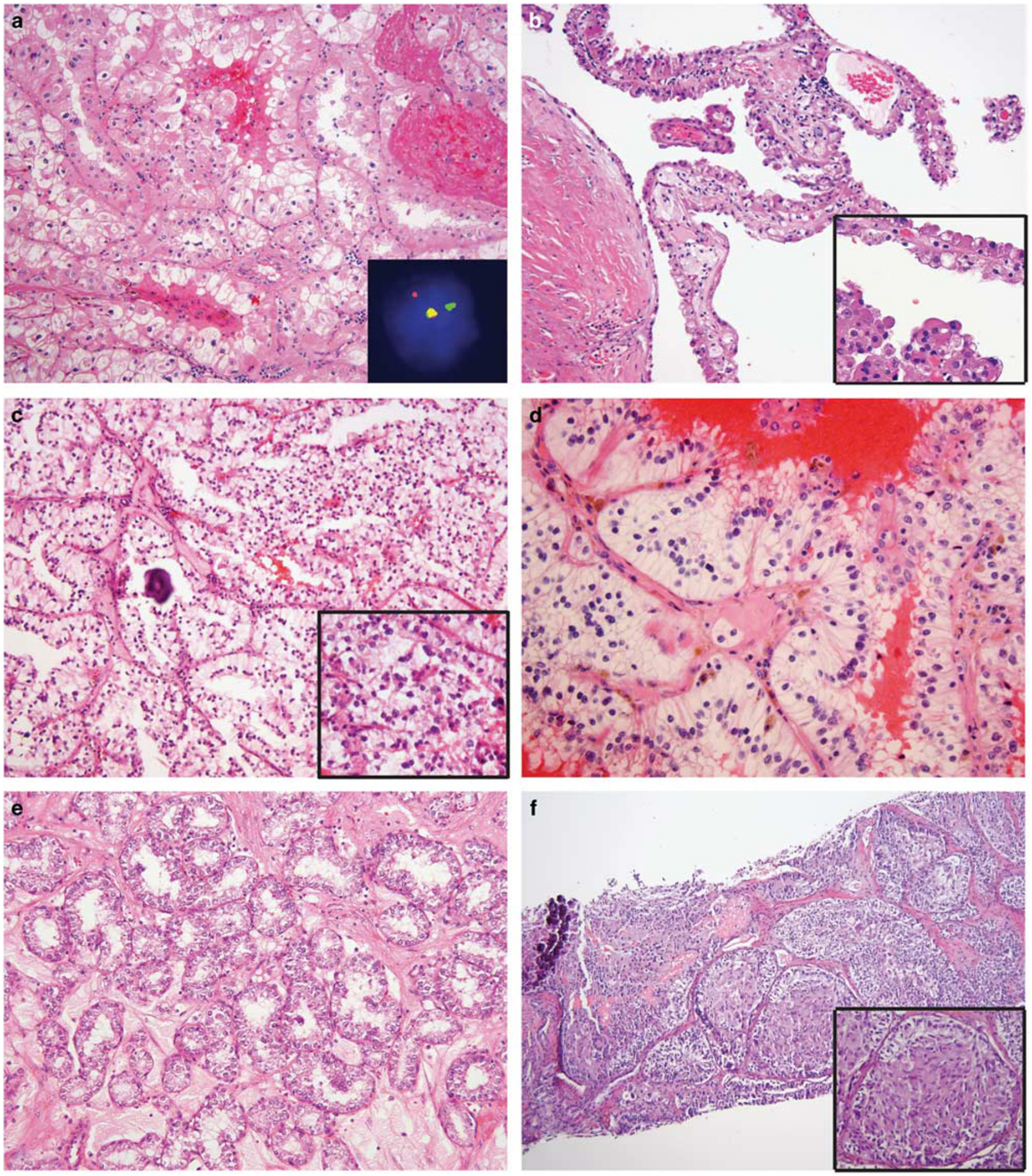

Figure 4 Morphologic spectrum of TFE3 translocation renal cell carcinoma, including (a) classic TFE3 translocation renal cell carcinoma morphology, H\&E, $\times 200$, inset: TFE3 FISH demonstrating split red and green signals indicating TFE3 translocation; (b) oncocytic renal cell carcinoma with cystic architecture, H\&E, $\times 200$, inset: H\&E, $\times 400$; (c) subnuclear clearing and linear nuclear array, H\&E, $\times 200$, inset: high World Health Organization/International Society of Urological Pathology nucleolar grade, H\&E, × 400; (d) extensive subnuclear clearing and linear nuclear array, H\&E, $\times 400$; (e) extensive tubular architecture, H\&E, $\times 200$; and (f) metastasis to liver with biphasic appearance including central swirled spindle cells, H\&E, × 100, inset: H\&E, $\times 200$. 

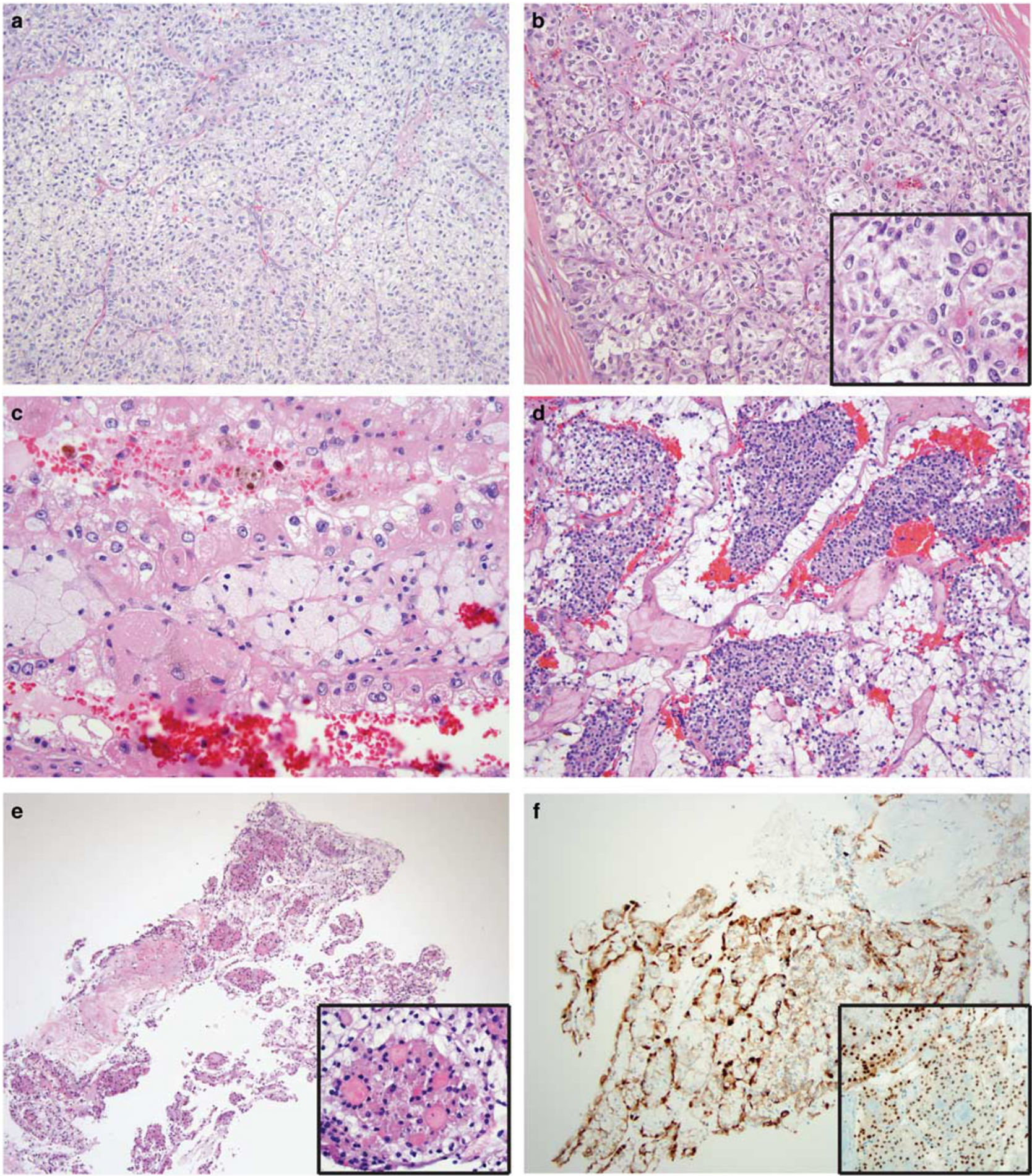

Figure 5 Morphologic spectrum of TFE3 translocation renal cell carcinoma, including (a) clear cell renal cell carcinoma-like morphology, H\&E, $\times 200$; (b) extensive nuclear pseudoinclusions, H\&E, $\times 200$, inset $\times 400$; (c) scattered collections of foamy histiocytes, H\&E, $\times 400$, and two cases with TFEB translocation renal cell carcinoma-like morphology including (d) a partial nephrectomy, H\&E, $\times 200$, and (e) a needle biopsy, H\&E, $\times 100$, inset: $\times 200$, with (f) immunohistochemical expression of pancytokeratin and PAX8 (inset) by tumor cells.

\section{Comparison of Renal Cell Carcinomas with and without MITF Aberrations}

To identify morphologic clues to the diagnosis of translocation renal cell carcinoma and/or TFEBamplified renal cell carcinoma, we compared the frequency of specific morphologic features across cases in our cohort, stratified by TFE3 and/or TFEB FISH status. Four morphologic features were significantly associated with the presence of an MITF aberration, compared with renal cell carcinoma 

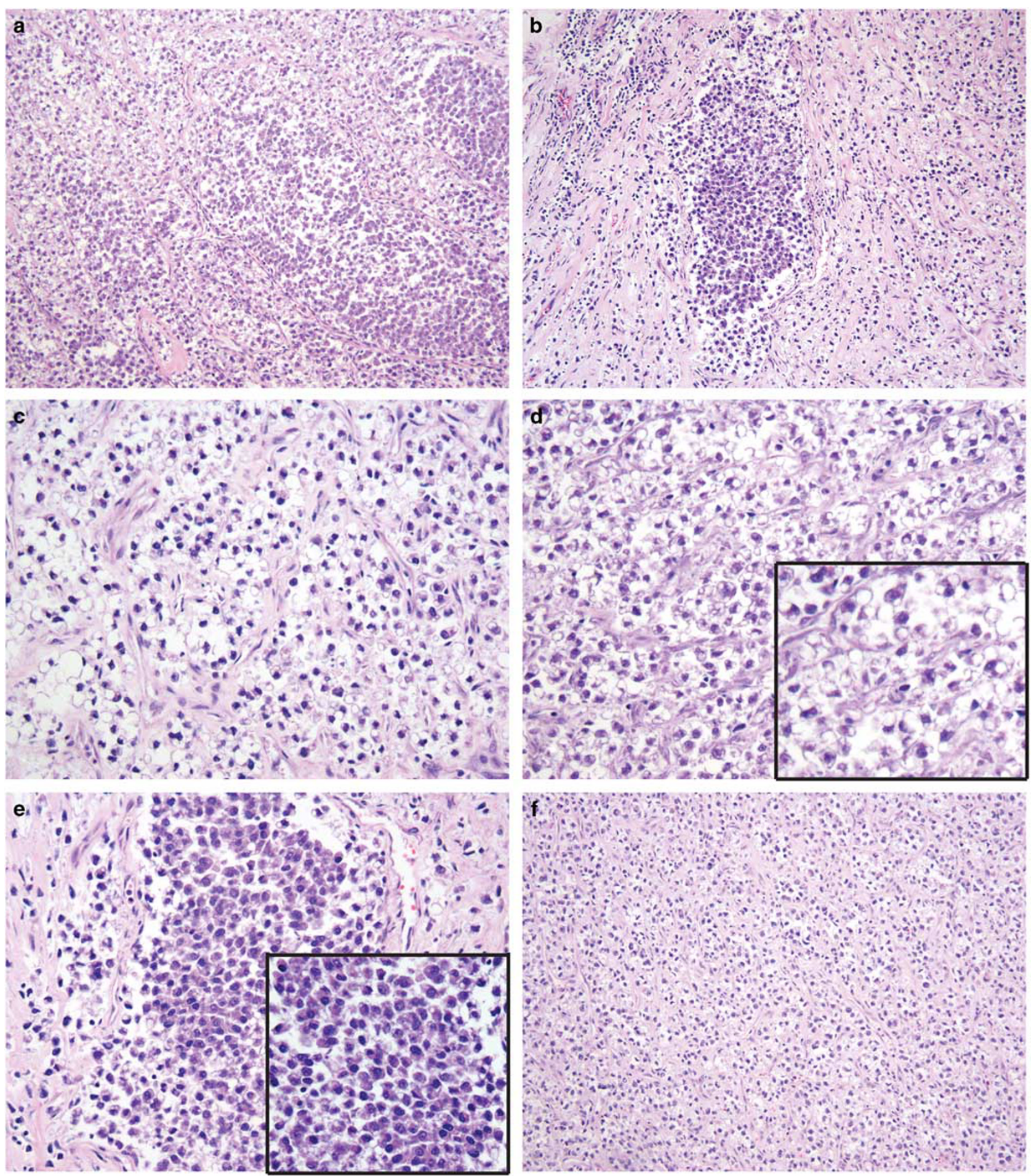

Figure 6 TFE3 translocation renal cell carcinoma arising in a horseshoe kidney, with biphasic morphology (a, b), H\&E, $\times 200$. The tumor is composed predominantly of cells with eosinophilic to clear cytoplasm, eccentric nuclei, and large vacuoles (c, d), H\&E, $\times 400$ (inset highlights vacuoles), with focal pockets of eosinophilic cells with high nucleus-to-cytoplasm ratio (e), H\&E, $\times 400$ (inset highlights increased nucleus-to-cytoplasm ratio). Other areas of the tumor mimic high-grade clear cell renal cell carcinoma (f), H\&E, $\times 200$.

without MITF aberrations: dual (eosinophilic and clear) cytoplasmic tones $(P=0.030)$, biphasic TFEB translocation renal cell carcinoma-like morphology $(P=0.002)$, psammomatous calcifications $(P=0.002)$, and nuclear pseudoinclusions $(P=0.001)$. Specifically, entrapped benign renal tubules were significantly associated with TFEB translocation $(P=0.01)$, while psammomatous calcifications were significantly 

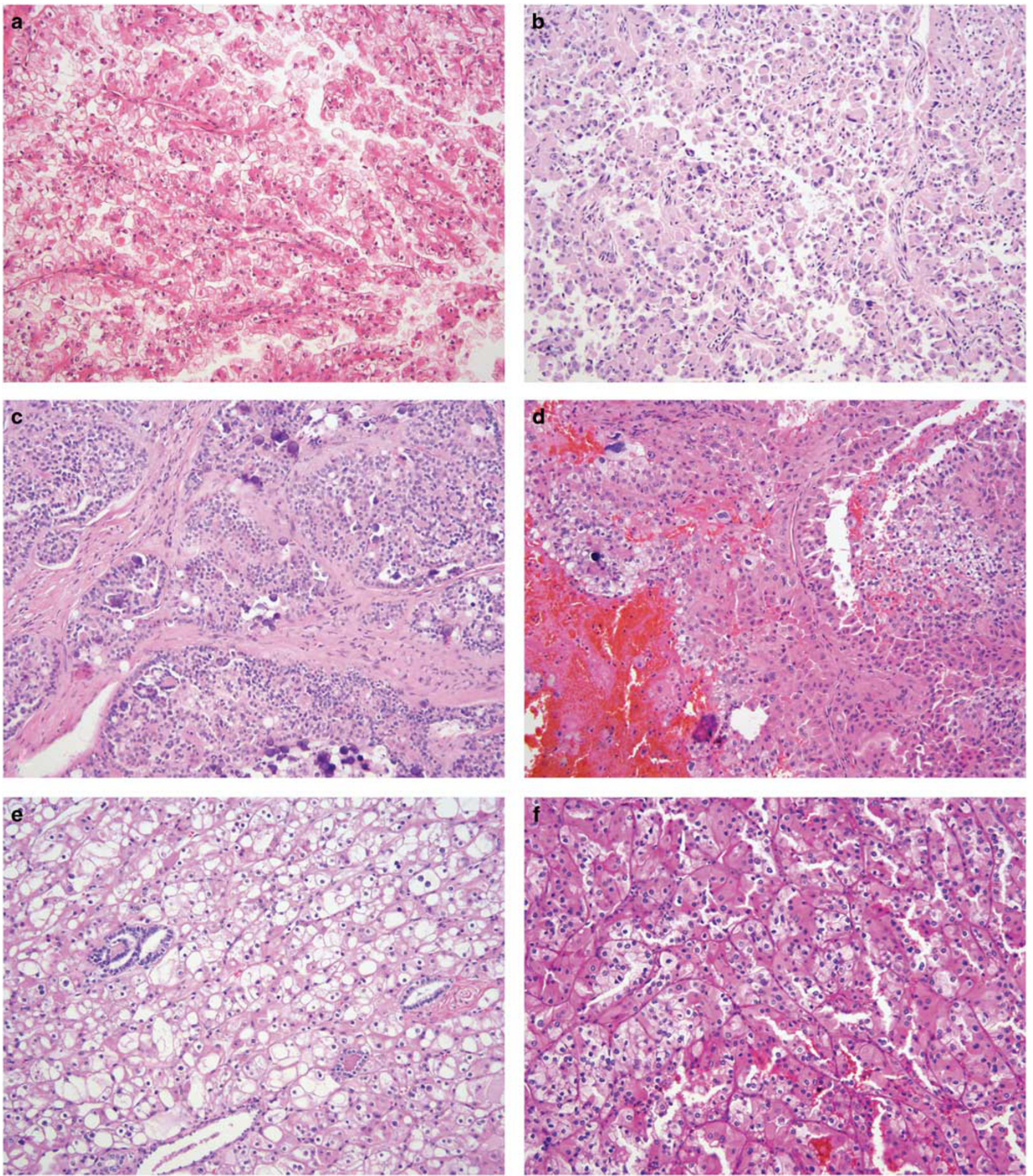

Figure 7 Renal cell carcinomas lacking MITF aberrations by TFE3 and TFEB FISH assays. (a) Clear cell renal cell carcinoma with morphology resembling TFE3 translocation renal cell carcinoma, H\&E, × 200; (b) high-grade oncocytic papillary renal cell carcinoma, H\&E, × 200; (c) unclassified renal cell carcinoma with biphasic populations including smaller cells surrounding psammoma bodies, H\&E, $\times 200$; (d) papillary renal cell carcinoma with second population of clear cells and psammomatous calcifications, H\&E, $\times 200$; (e) unclassified renal cell carcinoma with voluminous eosinophilic and clear cytoplasm and entrapped benign renal tubules, H\&E, $\times 200$; and (f) unclassified renal cell carcinoma with voluminous eosinophilic and clear cytoplasm, H\&E, × 200 .

associated with TFE3 translocations and TFEB translocations ( $P=0.002$ and $P=0.007$, respectively); interestingly, while clearly significantly associated with TFEB translocation (50\% of tumors), the biphasic TFEB translocation renal cell carcinomalike morphology was not specific for TFEB translocation, as it was also significantly associated with TFE3 translocation $(P=0.005)$. In addition, nuclear 
pseudoinclusions and subnuclear clearing with linear nuclear array were significantly associated with TFE3 translocation, compared with renal cell carcinoma without MITF aberrations $(P=0.0009$ and $P=0.0009$, respectively). The remaining morphologic features listed in Table 1 did not show statistically significant differences between tumor subgroups.

\section{Discussion}

Renal cell carcinomas with MITF aberrations, including TFE3 translocation renal cell carcinoma, TFEB translocation renal cell carcinoma, and TFEBamplified renal cell carcinoma, represent a morphologically heterogeneous group of primary renal tumors that nonetheless share molecular aberrations of the MITF family of transcription factors. Recognition of these uncommon tumors in routine clinical practice is increasingly important in the era of personalized medicine and targeted therapeutics, as they are molecularly distinct from other more common renal cell carcinoma subtypes, such as clear cell renal cell carcinoma and papillary renal cell carcinoma. Indeed, medicine is currently witnessing a significant expansion of molecular advancements leading to new diagnostic, prognostic, and therapeutic possibilities in the field of oncology. Even a correct subclassification into the 'unclassified' category might carry significant theranostic associations. 29

Since the initial description of TFE3 and TFEB translocation renal cell carcinoma, multiple studies have reported novel morphologic features in these tumors, ${ }^{7,13,21,23,24,30-47}$ which overlap with each other, as well as other more common renal cell carcinoma subtypes. In addition, although only a relatively small number of cases have been described, the recently reported TFEB-amplified renal cell carcinomas also show variable morphologic patterns, ${ }^{16-18,48,49}$ which may overlap with other more common renal cell carcinoma subtypes. Although immunohistochemical staining can be helpful in the clinical work-up of possible cases of renal cell carcinoma with MITF aberrations, even the most sensitive and specific immunohistochemical markers (TFE3, TFEB, and cathepsin K) are less reliable than FISH for TFE3 and TFEB aberrations in most instances, and in some cases (ie, clinical trial enrollment), evidence of MITF aberration by FISH or next-generation sequencing may be required. Thus, at our institution, we have established a genitourinary service line laboratory that provides clinicalgrade diagnostic TFE3 and TFEB FISH assays in a Clinical Laboratory Improvement Amendments (CLIA)-certified laboratory. In this manuscript, we described our experience with 85 consecutive renal cell carcinoma cases evaluated for MITF aberrations and reported 31 novel FISH-confirmed cases, including 6 TFEB-amplified renal cell carcinoma, 4 TFEB translocation renal cell carcinoma, and 21 TFE3 translocation renal cell carcinoma. This cohort is unique in that all tumors submitted for FISH analysis were considered to be suspicious for the presence of a MITF aberration on clinical, morphologic, and/or immunophenotypic grounds; even in this highly enriched cohort, however, only a subset of tumors $(37 \%)$ were subsequently shown to harbor MITF aberrations at the genomic level, indicating the potential need for the elaboration of additional morphologic clues to assist in the diagnosis of renal cell carcinoma with MITF aberrations. Indeed, our systematic morphologic assessment of tumors in this cohort revealed a subset of features which might aid in the distinction of renal cell carcinoma with MITF aberrations from other renal cell carcinoma subtypes (including unclassified tumors); these include dual (eosinophilic and clear) cytoplasmic tones, biphasic TFEB translocation renal cell carcinoma-like morphology, psammomatous calcifications, and nuclear pseudoinclusions. While the first three features have been consistently previously reported in renal cell carcinomas with MITF aberrations, this is to our knowledge the first report of an association between the presence of nuclear pseudoinclusions and MITF aberrations (in particular, TFE3 translocation).

Although TFEB-amplified renal cell carcinoma represented $<10 \%$ of renal cell carcinoma associated with TFEB alterations in Dr Pedram Argani's files $^{16}$ and only $1 \%$ of cases in the TCGA papillary renal cell carcinoma study, ${ }^{2}$ TFEB-amplified renal cell carcinomas are more common than TFEB translocation renal cell carcinomas in our cohort. Based on the largest series $(n=8$ and $n=25)$ reported so far, ${ }^{16,17}$ the median age at diagnosis of TFEBamplified renal cell carcinoma is in the mid-to-late seventh decade of life, and there is a slight male predominance; our data conform to both these prior findings. In addition, all TFEB-amplified renal cell carcinomas in our cohort were of high World Health Organization/International Society of Urological Pathology nucleolar grade (four grade 3 , two grade 4), consistent with what Argani et al (six grade 3, two grade 4) previously reported. Similarly, Gupta et al reported cases with any degree of TFEB amplification (at least five or more copies of the probe per tumor nucleus), and found that 91\% (20/22) were of high World Health Organization/International Society of Urological Pathology nuclear grade (3 or above). ${ }^{16,17}$ The vast majority (83\%) of TFEB-amplified renal cell carcinomas in our cohort presented with locally advanced disease (pT3 or above). Similarly, in the large cohort reported by Gupta et al, ${ }^{17} 76 \%$ of patients presented with pT2 disease or higher, and $52 \%$ presented with pT3 disease or higher. Nearly half of the patients in their cohort developed documented regional or distant metastasis over a mean follow-up duration of 101 months.

The initial reported morphologic patterns for TFEB-amplified renal cell carcinomas include tumors with focal papillary areas with clustering of 
small cells in acinar formations lacking basement membrane material, ${ }^{16}$ prominent macronucleoli with perinucleolar halos (in the presence of diffuse Melan-A expression), ${ }^{16}$ biphasic with smaller pale epithelioid cells associated with large clusters of polygonal eosinophilic cells (often present within the lumen of acini), ${ }^{16}$ low-grade nuclei in a background of oncocytic and papillary features, ${ }^{48}$ and eosinophilic tubulopapillary morphology with features resembling either hereditary leiomyomatosis and renal cell carcinoma-associated renal cell carcinoma or eosinophilic variant of chromophobe renal cell carcinoma. ${ }^{18}$ Additionally, one of the cases reported by Peckova et $a l^{49}$ to have both TFEB amplification and rearrangement had foci with highgrade oncocytic and papillary morphology.

In our cohort, TFEB-amplified renal cell carcinomas showed morphologic overlap with papillary renal cell carcinoma and clear cell renal cell carcinoma. Notably, four of six cases $(67 \%)$ in our cohort were high-grade oncocytic tumors with papillary architecture and foci with orderly polarization of nuclei in the mid to apical aspect of large oncocytic cells. The two cases resembling high-grade clear cell renal cell carcinoma had nested architecture and diffuse dual cytoplasmic tones. The recent study published by Gupta et $a 1^{17}$ similarly demonstrated that TFEB amplification was most prevalent in renal cell carcinomas initially diagnosed as either papillary renal cell carcinoma or unclassified renal cell carcinoma. In their cohort, 76\% (19/25) of TFEBamplified renal cell carcinomas showed prominent tubulopapillary architecture, oncocytic cytoplasm, and high World Health Organization/International Society of Urological Pathology nucleolar grade. Although Gupta et al reported focal areas with biphasic TFEB translocation renal cell carcinomalike morphology in 3 of 25 TFEB amplified renal cell carcinomas, none of the cases in our cohort exhibited the classic biphasic morphology of TFEB translocation renal cell carcinoma. One of our TFEB-amplified renal cell carcinomas had foci of smaller cells forming acinar structures without basement membrane material, and another (with clear cell renal cell carcinoma-like morphology) demonstrated entrapped benign renal tubules as are commonly seen in TFEB translocation renal cell carcinoma. To our knowledge, well-developed biphasic TFEB translocation renal cell carcinoma-like morphology has never been reported in TFEB-amplified renal cell carcinoma.

Importantly, although the number of TFEB-amplified renal cell carcinoma cases in our cohort was small, there were no significant morphologic differences between TFEB-amplified renal cell carcinoma and renal cell carcinoma without MITF aberrations, indicating the need for a high level of clinical suspicion to identify these cases. In particular, locally advanced tumors with papillary features, oncocytic cytoplasm, and orderly polarization of nuclei within the mid to apical aspects of voluminous oncocytic cells occurring in older patients might be one trigger to evaluate for the possibility of TFEB-amplified renal cell carcinoma. Fifty percent of TFEB-amplified renal cell carcinomas showed nuclear pseudoinclusions; given the detected novel association between this morphologic feature and MITF aberrations in our study, future morphologic studies on TFEB-amplified renal cell carcinoma should document the frequency of this finding and analyze its potential diagnostic utility. Psammomatous calcifications were identified in only $16.7 \%$ of TFEB-amplified RCCs; thus, this morphologic feature may be less common in TFEBamplified RCCs than RCCs with other MiT family aberrations (specifically TFE3 t-RCC).

Similar to TFEB translocation renal cell carcinomas, TFEB-amplified renal cell carcinomas show aberrant melanocytic marker expression; however, TFEB-amplified renal cell carcinomas often show more variable melanocytic marker expression by IHC as compared with TFEB translocation renal cell carcinomas. ${ }^{16}$ The five TFEB-amplified renal cell carcinomas in our cohort that were interrogated for Melan-A expression showed either patchy or diffuse expression. One of the two cases evaluated for HMB-45 showed very focal expression, whereas the other was negative. Similarly, Argani et $a l^{16}$ and Gupta et $a l^{17}$ have reported Melan-A expression in a larger subset of TFEB-amplified renal cell carcinomas than HMB-45 expression in 3/8 cases; expression of melanocytic markers was more common in cases with high-level amplification.

All four of the TFEB-amplified renal cell carcinomas that were immunohistochemically evaluated for pancytokeratin in our cohort showed patchy or positive expression, indicating that absence of pancytokeratin expression might not be particularly useful for detection of TFEB-amplified renal cell carcinomas.

TFE3 translocation renal cell carcinomas were initially described to have clear cells with papillary architecture and numerous psammoma bodies. In particular, ASPL-TFE3 renal cell carcinomas have been reported to have large tumor cells with voluminous cytoplasm, discrete cell borders, vesicular chromatin, and prominent nucleoli, displaying alveolar or pseudopapillary architecture and numerous psammoma bodies. ${ }^{30}$ PRCC-TFE3 renal cell carcinomas have been reported to have less abundant cytoplasm, a more compact nested growth pattern, and fewer psammoma bodies. ${ }^{31}$ Other reported morphologies include clear cell renal cell carcinoma-like with a delicate vascular network, ${ }^{32,33}$ multilocular cystic renal cell carcinoma-like, ${ }^{21,32}$ sarcomatoid, ${ }^{21}$ oncocytoma-like, ${ }^{21}$ carcinoid-like, ${ }^{21}$ urothelial carcinoma in situ-like growth pattern, ${ }^{21}$ infiltrating high-grade urothelial carcinoma-like, ${ }^{32}$ signet ring-like with microcystic growth pattern, ${ }^{13}$ Fuhrman nuclear grade 4 with solid/syncytial growth pattern, ${ }^{13}$ TFEB translocation renal cell carcinoma-like, ${ }^{24,34,35}$ mucinous tubular and spindle 
cell carcinoma-like, ${ }^{34}$ and collecting duct carcinomalike. ${ }^{34}$ In 2013, Rao et al ${ }^{32}$ published a morphologic comparison between 17 TFE3 translocation renal cell carcinomas and 7 cases that were considered unclassified renal cell carcinomas due to negative TFE3 dual-color break-apart FISH. ${ }^{32}$ This group found that psammoma bodies, hyaline stroma, and pigment were more likely to be seen in TFE3 translocation renal cell carcinomas, whereas cholesterol clefts were more likely to be seen in unclassified renal cell carcinoma mimicking translocation renal cell carcinoma. To our knowledge, this is the only previous study that has reported data from a systematic assessment of both positive and negative cases. In our cohort, the most common architectural patterns for TFE3 translocation renal cell carcinoma were papillary and nested, and our data confirm previous findings that dual (eosinophilic and clear) cytoplasmic tones and psammomatous calcifications are more commonly seen in TFE3 translocation renal cell carcinoma. In addition, our cohort of TFE3 translocation renal cell carcinomas included two cases with striking morphologic resemblance to classic TFEB translocation renal cell carcinomas, as has been described previously by other groups. ${ }^{24,34,35}$ This highlights the importance of ancillary testing in correctly classifying these renal cell carcinomas.

We found that tumors demonstrating subnuclear clearing with linear nuclear array are significantly associated with TFE3 translocation. Although reverse polarity (location of nuclei towards the middle or upper pole of cells) is most commonly seen in clear cell papillary renal cell carcinoma, the distinction between clear cell papillary renal cell carcinoma and renal cell carcinomas with MITF aberrations is not always clear-cut and the considerably worse prognosis associated with translocation renal cell carcinoma makes this distinction critical. In contrast to the high-grade renal cell carcinomas we describe with focal or diffuse subnuclear clearing and linear array of mid-to-apical nuclei, clear cell papillary renal cell carcinomas are almost always low grade (most commonly Fuhrman nuclear grade 2 ) and confined to the kidney. ${ }^{36}$ Two different groups recently reported similar morphology in NONO-TFE3 renal cell carcinomas. ${ }^{23,33}$ The published cases of NONO-TFE3 renal cell carcinoma demonstrate nested to papillary architecture, psammoma bodies, and subnuclear clearing resulting in suprabasal nuclear palisading similar to what is seen in clear cell papillary renal cell carcinoma. Xia et $a l^{23}$ reported their cases to be nucleolar grade 2, and often accompanied by sheets of epithelial cells. Similarly, one morphologically similar TFE3 translocation renal cell carcinoma in our cohort and another in the literature ${ }^{37}$ have been of low nucleolar grade. The related SFPQ/PSF-TFE3 renal cell carcinomas also frequently show subnuclear clearing. ${ }^{33}$ Supporting evidence for the diagnosis of MITF aberration renal cell carcinoma in tumors with subnuclear clearing includes young age at presentation, metastasis, admixed papillary and alveolar architecture, high columnar cells with indistinct cell borders, flocculent eosinophilic cytoplasm, nuclear pseudoinclusions, occasional mitotic figures, frequent psammoma bodies, hyaline degeneration of stroma, and little to no immunoreactivity for CK7. ${ }^{23,33,37}$

Interestingly, more than half of the TFE3 translocation renal cell carcinomas in our cohort showed at least focal nuclear pseudoinclusions. In one case, nuclear pseudoinclusions were seen focally throughout the majority of the tumor, with one nodule demonstrating pseudoinclusions in the majority of nuclei. The presence of nuclear pseudoinclusions was significantly associated with detection of TFE3 translocation in comparison with no MITF aberration $(P=0.001)$; to our knowledge, this association has not previously been reported in the literature.

TFEB translocation renal cell carcinomas tend to have a biphasic appearance with large epithelioid cells and small cells clustered around nodules of basement membrane material. ${ }^{7}$ The frequency and quality of 'pseudorosettes' or small cells surrounding hyaline basement membrane material is variable, and this component is not always seen on initial sections. ${ }^{39}$ These 'pseudorosettes' are sometimes found at the end of elongated branching tubules lined by larger neoplastic cells. ${ }^{39}$ It is common to see entrapped benign renal tubules in the periphery of TFEB translocation renal cell carcinomas. ${ }^{39,40}$ Reported variant morphologies of TFEB translocation renal cell carcinomas include oncocytomalike, ${ }^{40}$ oncocytic and papillary, ${ }^{40}$ clear cell renal cell carcinoma-like, ${ }^{38,40-43}$ multilocular cystic renal cell carcinoma-like, ${ }^{38}$ TFE3 translocation renal cell carcinoma-like, ${ }^{41,49}$ classic chromophobe renal cell carcinoma-like with a biphasic population, ${ }^{43}$ epithelioid angiomyolipoma-like, ${ }^{43}$ tubulocystic renal cell carcinoma-like, ${ }^{44}$ solid sheets of medium polygonal cells with small round nuclei with foci of papillary and tubular architecture, ${ }^{13}$ cystic spaces lined by epithelioid cells and containing small nodules of hyaline material surrounded by small cells with pyknotic nuclei and clear cytoplasm in a background of more classic features, ${ }^{45}$ and extensive sclerosis and metaplastic bone formation. ${ }^{46}$

In our cohort, the classic biphasic appearance with smaller cells surrounding basement membrane material and psammomatous calcifications were both associated with TFEB translocation, as previously reported. These features, in combination with Melan-A expression, are suggestive of the diagnosis of TFEB translocation renal cell carcinoma. In contrast to the three cases for which TFEB translocation renal cell carcinoma was the top morphologic differential diagnosis based on the above features, one of the TFEB translocation renal cell carcinomas in our cohort demonstrated predominantly papillary architecture with a prominent lymphocytic infiltrate. To our knowledge, this morphology has not 
previously been reported in a TFEB translocation renal cell carcinoma; however, case 3 from a 2007 series by Meyer et $a l^{47}$ was a stage T1b TFE3 translocation renal cell carcinoma with clear cells with voluminous cytoplasm and distinct cell borders forming papillary structures with admixed lymphocytes. An additional case with TFEB translocation and amplification reported by Peckova et $a l^{49}$ showed occasional lymphocytes in the interstitium. This further demonstrates the potential for morphologic overlap between subtypes of renal cell carcinoma with MITF aberrations.

Strengths of this study include the relatively large consecutive cohort of renal tumors clinically, morphologically, and/or immunophenotypically suspicious for translocation renal cell carcinoma processed with TFE3 and TFEB FISH assays at a single large academic institution (170 assays performed on 85 tumors), yielding identification of MITF aberrations in greater than one-third of cases. These FISH assays were performed in a CLIAcertified laboratory on whole formalin-fixed, paraffin-embedded specimens of various sizes, from needle biopsies to resections, with demonstration of positive FISH results in some needle biopsy specimens. Availability of confirmatory FISH results allowed us to specifically delineate morphologic and immunophenotypic features associated with MITF aberrations, in a cohort overall selected based on clinical and/or immunomorphologic suspicion of translocation renal cell carcinoma. Additionally, we report clinical, morphologic, and immunophenotypic features of six new TFEB-amplified renal cell carcinomas confirmed by FISH. We provide a systematic morphologic assessment of this cohort, including comparison between cases that are negative and positive by FISH analyses.

Weaknesses of this study include the limited clinical and immunohistochemical information available for some of the consultation cases, lack of utilization of TFE3 or TFEB immunohistochemistry in most cases, and the inherent bias in what general surgical pathologists versus genitourinary pathologists may consider to be suspicious morphology for translocation renal cell carcinoma. Our morphologic assessment of consultation cases was limited by the number of slides available to us; this is a limitation given the known heterogeneity of morphology in renal cell carcinomas with MITF aberrations. We did not aim to evaluate the relative merits of IHC and FISH for diagnosis of MITF aberration renal cell carcinomas. The small number of cases with TFEB aberrations limited our ability to demonstrate statistically significant associations between morphologic features and the presence of TFEB aberrations.

Given the broad variation in morphology both within and between different MITF aberration renal cell carcinomas and overlap with a number of other subtypes of renal cell carcinoma, pathologists might need to keep a low threshold for evaluating renal cell carcinomas for MITF aberrations in the correct context. Although clinical TFE3 and TFEB FISH assays performed with dual-color break-apart probes cannot detect subtle chromosomal inversions, they are of great utility in correctly classifying certain high-grade renal cell carcinomas including those with TFEB amplification (which portends a poorer prognosis than TFEB translocation renal cell carcinoma despite similar overexpression of TFEB). Some groups have also developed fusion FISH assays to detect specific intrachromosomal translocations. ${ }^{27}$ In suspicious cases that lack 'classic' morphology, the complementary methods of FISH and IHC may be helpful to establish the correct diagnosis and facilitate potential clinical trial enrollment. Based on our institutional experience, TFEB amplification may be at least as common as TFEB translocation as a genomic mechanism driving TFEB overexpression in adults; this needs to be validated by further studies. Our results support the notion that prominent papillary architecture, oncocytic cytoplasm, and high nucleolar grade are helpful features to identify cases that would benefit from FISH evaluation.

\section{Disclosure/conflict of interest}

The authors declare no conflict of interest.

\section{References}

1 Moch H, Amin M, Argani P, et al. Tumours of the kidney. In: Moch H, Humphrey PA, Ulbright TM, et al (eds). WHO Classification of Tumours of the Urinary System and Male Genital Organ, 4th edn. International Agency for Research on Cancer (IARC) Press: Lyon, France, 2016, pp 14-17.

2 Cancer Genome Atlas Research Network. Comprehensive molecular characterization of papillary renal-cell carcinoma. N Engl J Med 2016;374:135-145.

3 Creighton CJ, Morgan M, Gunaratne PH, et al. Comprehensive molecular characterization of clear cell renal cell carcinoma. Nature 2013;499:43-49.

4 Chen F, Zhang Y, Şenbabaoğlu Y, et al. Multilevel genomics-based taxonomy of renal cell carcinoma. Cell Rep 2016;14:2476-2489.

5 Davis CF, Ricketts CJ, Wang M, et al. The somatic genomic landscape of chromophobe renal cell carcinoma. Cancer Cell 2014;26:319-330.

6 Mehra R, Vats P, Cieslik M, et al. Biallelic alteration and dysregulation of the Hippo pathway in mucinous tubular and spindle cell carcinoma of the kidney. Cancer Discov 2016;6:1258-1266.

7 Argani P. MiT family translocation renal cell carcinoma. Semin Diagn Pathol 2015;32:103-113.

8 Udager AM, Mehra R. Morphologic, molecular, and taxonomic evolution of renal cell carcinoma: a conceptual perspective with emphasis on updates to the 2016 World Health Organization Classification. Arch Pathol Lab Med 2016;140: 1026-1037.

9 Moch H, Cubilla AL, Humphrey PA, et al. The 2016 WHO Classification of Tumours of the Urinary System 
and Male Genital Organs-Part A: Renal, Penile, and Testicular Tumours. Eur Urol 2016;70:93-105.

10 Schmidt LS, Linehan WM. Genetic predisposition to kidney cancer. Semin Oncol 2016;43:566-574.

11 Srigley JR, Delahunt B, Eble JN, et al. The International Society of Urological Pathology (ISUP) Vancouver Classification of Renal Neoplasia. Am J Surg Pathol 2013;37:1469-1489.

12 Sukov WR, Hodge JC, Lohse CM, et al. TFE3 rearrangements in adult renal cell carcinoma: clinical and pathologic features with outcome in a large series of consecutively treated patients. Am J Surg Pathol 2012;36:663-670.

13 Zhong M, DeAngelo P, Osborne L, et al. Translocation renal cell carcinomas in adults: a single-institution experience. Am J Surg Pathol 2012;36:654-662.

14 Falzarano SM, McKenney JK, Montironi R, et al. Renal cell carcinoma occurring in patients with prior neuroblastoma: a heterogenous group of neoplasms. Am J Surg Pathol 2016;40:989-997.

15 Hora M, Urge T, Trávníček I, et al. MiT translocation renal cell carcinomas: two subgroups of tumours with translocations involving $6 \mathrm{p} 21[\mathrm{t}(6 ; 11)]$ and Xp11.2 [t (X;1 or X or 17)]. Springerplus 2014;3:245.

16 Argani P, Reuter VE, Zhang L, et al. TFEB-amplified renal cell carcinomas: an aggressive molecular subset demonstrating variable melanocytic marker expression and morphologic heterogeneity. Am J Surg Pathol 2016;40:1484-1495.

17 Gupta S, Johnson SH, Vasmatzis G, et al. TFEB-VEGFA (6p21.1) co-amplified renal cell carcinoma: a distinct entity with potential implications for clinical management. Mod Pathol 2017;30:998-1012.

18 Williamson SR, Grignon DJ, Cheng L, et al. Renal cell carcinoma with chromosome $6 \mathrm{p}$ amplification including the TFEB gene: a novel mechanism of tumor pathogenesis? Am J Surg Pathol 2016;41:287-298.

19 Udager AM, Alva A, Mehra R. Current and proposed molecular diagnostics in a genitourinary service line laboratory at a tertiary clinical institution. Cancer J 2014;20:29-42.

20 Mosquera JM, Dal Cin P, Mertz KD, et al. Validation of a TFE3 break-apart FISH assay for Xp11.2 translocation renal cell carcinomas. Diagn Mol Pathol 2011;20: 129-137.

21 Green WM, Yonescu R, Morsberger L, et al. Utilization of a TFE3 break-apart FISH assay in a renal tumor consultation service. Am J Surg Pathol 2013;37: 1150-1163.

22 Argani P, Lal P, Hutchinson B, et al. Aberrant nuclear immunoreactivity for TFE3 in neoplasms with TFE3 gene fusions: a sensitive and specific immunohistochemical assay. Am J Surg Pathol 2003;27:750-761.

23 Xia Q, Wang Z, Chen N, et al. Xp11.2 translocation renal cell carcinoma with NONO-TFE3 gene fusion: morphology, prognosis, and potential pitfall in detecting TFE3 gene rearrangement. Mod Pathol 2016;30: 416-426.

24 Argani P, Zhang L, Reuter VE, et al. RBM10-TFE3 renal cell carcinoma: a potential diagnostic pitfall due to cryptic intrachromosomal Xp11.2 inversion resulting in false-negative TFE3 FISH. Am J Surg Pathol 2017;41: 655-662.

25 Udager AM, Shi Y, Tomlins SA, et al. Frequent discordance between ERG gene rearrangement and ERG protein expression in a rapid autopsy cohort of patients with lethal, metastatic, castration-resistant prostate cancer. Prostate 2014;74:1199-1208.

26 Mehra R, Tomlins SA, Yu J, et al. Characterization of TMPRSS2-ETS gene aberrations in androgenindependent metastatic prostate cancer. Cancer Res 2008;68:3584-3590.

27 Mehra R, Han B, Tomlins SA, et al. Heterogeneity of TMPRSS2 gene rearrangements in multifocal prostate adenocarcinoma: molecular evidence for an independent group of diseases. Cancer Res 2007;67:7991-7995.

28 Mehra R, Tomlins SA, Shen R, et al. Comprehensive assessment of TMPRSS2 and ETS family gene aberrations in clinically localized prostate cancer. Mod Pathol 2007;20:538-544.

29 Chen YB, Xu J, Skanderup AJ, et al. Molecular analysis of aggressive renal cell carcinoma with unclassified histology reveals distinct subsets. Nat Commun 2016;7: 13131.

30 Argani P, Antonescu CR, Illei PB, et al. Primary renal neoplasms with the $A S P L-T F E 3$ gene fusion of alveolar soft part sarcoma: a distinctive tumor entity previously included among renal cell carcinomas of children and adolescents. Am J Pathol 2001;159:179-192.

31 Argani P, Antonescu CR, Couturier J, et al. PRCC-TFE3 renal carcinomas: morphologic, Immunohistochemical, ultrastructural, and molecular analysis of an entity associated with the $\mathrm{t}(\mathrm{x} ; 1)(\mathrm{p} 11.2 ; \mathrm{q} 21)$. Am J Surg Pathol 2002;26:1553-1566.

32 Rao Q, Williamson SR, Zhang S, et al. TFE3 break-apart FISH has a higher sensitivity for Xp11.2 translocationassociated renal cell carcinoma compared with TFE3 or Cathepsin K immunohistochemical staining alone: expanding the morphologic spectrum. Am J Surg Pathol 2013;37:804-815.

33 Argani P, Zhong M, Reuter V, et al. TFE3-fusion variant analysis defines specific clinicopathologic associations among Xp11 translocation cancers. Am J Surg Pathol 2016;40:723-737.

34 Argani P, Olgac S, Tickoo SK, et al. Xp11 translocation renal cell carcinoma in adults: expanded clinical, pathologic, and genetic spectrum. Am J Surg Pathol 2007;31:1149-1160.

35 Argani P, Lui MY, Couturier J, et al. A novel CLTCTFE3 gene fusion in pediatric renal adenocarcinoma with $\mathrm{t}(\mathrm{X} ; 17)(\mathrm{p} 11.2 ; \mathrm{q} 23)$. Oncogene 2003;22:5374-5378.

36 Williamson SR, Eble JN, Cheng L, et al. Clear cell papillary renal cell carcinoma: differential diagnosis and extended immunohistochemical profile. Mod Pathol 2013;26:697-708.

37 Parihar A, Tickoo SK, Kumar S, et al. Xp11 translocation renal cell carcinoma morphologically mimicking clear cell-papillary renal cell carcinoma in an adult patient: report of a case expanding the morphologic spectrum of Xp11 translocation renal cell carcinomas. Int J Surg Pathol 2015;23:234-237.

38 Smith NE, Illei PB, Allaf $\mathrm{M}$, et al. $\mathrm{t}(6 ; 11)$ renal cell carcinoma (RCC): expanded immunohistochemical profile emphasizing novel RCC markers and report of 10 new genetically confirmed cases. Am J Surg Pathol 2014;38:604-614.

39 Petersson F, Vaněček T, Michal M, et al. A distinctive translocation carcinoma of the kidney; 'rosette forming,' t(6;11), HMB45-positive renal tumor: a histomorphologic, immunohistochemical, ultrastructural, and molecular genetic study of 4 cases. Human Pathol 2012;43:726-736. 
40 Argani P, Yonescu R, Morsberger L, et al. Molecular confirmation of $\mathrm{t}(6 ; 11)(\mathrm{p} 21 ; \mathrm{q} 12)$ renal cell carcinoma in archival paraffin-embedded material using a breakapart TFEB FISH assay expands its clinicopathologic spectrum. Am J Surg Pathol 2012;36:1516-1526.

41 Inamura K, Fujiwara M, Togashi Y, et al. Diverse fusion patterns and heterogeneous clinicopathologic features of renal cell carcinoma with $\mathrm{t}(6 ; 11)$ translocation. Am J Surg Pathol 2012;36:35-42.

42 Lilleby W, Vlatkovic L, Meza-Zepeda LA, et al. Translocational renal cell carcinoma $(\mathrm{t}(6 ; 11)(\mathrm{p} 21 ; \mathrm{q} 12)$ with transcription factor EB (TFEB) amplification and an integrated precision approach: a case report. J Med Case Rep 2015;9:281.

43 Rao Q, Liu B, Cheng L, et al. Renal cell carcinomas with $\mathrm{t}(6 ; 11)(\mathrm{p} 21 ; \mathrm{q} 12)$ a clinicopathologic study emphasizing unusual morphology, novel Alpha-TFEB gene fusion point, immunobiomarkers, and ultrastructural features, as well as detection of the gene fusion by fluorescence in situ hybridization. Am J Surg Pathol 2012;36:1327-1338.

44 Rao Q, Zhang XM, Tu P, et al. Renal cell carcinomas with $t(6 ; 11)(p 21 ; q 12)$ presenting with tubulocystic renal cell carcinoma-like features. Int J Clin Exp Pathol 2013;6:1452-1457.

45 Suárez-Vilela D, Izquierdo-García F, Méndez-Álvarez JR, et al. Renal translocation carcinoma with expression of TFEB: presentation of a case with distinctive histological and immunohistochemical features. Int J Surg Pathol 2011;19:506-509.

46 Williamson SR, Eble JN, Palanisamy N, et al. Sclerosing TFEB rearrangement renal cell carcinoma: a recurring histologic pattern. Hum Pathol 2016;62:175-179.

47 Meyer PN, Clark JI, Flanigan RC, et al. Xp11.2 translocation renal cell carcinoma with very aggressive course in five adults. Am J Clin Pathol 2007;128: 70-79.

48 Durinck S, Stawiski EW, Pavía-Jiménez A, et al. Spectrum of diverse genomic alterations define nonclear cell renal carcinoma subtypes. Nat Genet 2015;47: 13-21.

49 Peckova K, Vanecek T, Martinek P, et al. Aggressive and nonaggressive translocation $\mathrm{t}(6 ; 11)$ renal cell carcinoma: comparative study of 6 cases and review of the literature. Ann Diagn Pathol 2014;18:351-357.

Supplementary Information accompanies the paper on Modern Pathology website (http://www.nature.com/ modpathol) 